\title{
Chemiresistor-type NO gas sensor based on nickel phthalocyanine thin films
}

\author{
Kuo-Chuan Ho*, Yi-Ham Tsou \\ Department of Chemical Engineering, National Taiwan University, Taipei 10617, Taiwan
}

\begin{abstract}
The sensing characteristics of nickel phthalocyanine (NiPc) thin films for use in a chemiresistor-type nitric oxide gas sensor are discussed. The gas-sensing properties, including current transient, sensitivity, response time, and aging, are studied. A kinetic model proposed in the literature for sensing $\mathrm{NO}_{2}$ with lead phthalocyanine $(\mathrm{PbPc})$ thin films, in which adsorption involves displacement of surface adsorbed $\mathrm{O}_{2}$ from a range of heterogeneous sites, can be used to explain our experimental results. It is inferred that exposure to NO concentrations lower than $50 \mathrm{ppm}$ only involves the population of weak adsorption sites, while exposure to NO concentrations higher than $50 \mathrm{ppm}$ may involve the population of stronger adsorption sites. Repeated step changes in NO concentrations of $50 \mathrm{ppm}$ could result in a significant change in response currents within the first five cycles, presumably due to the presence of an irreversible adsorption. Further analysis of current responses reveals that the lower the concentration of NO, the larger the sensitivity. For a lower concentration range, between 5 and $50 \mathrm{ppm} \mathrm{NO}$, the sensitivity lies between 0.41 and 0.42 , while for a higher concentration range, between 50 and 500 ppm, the sensitivity decreases to about 0.17 to 0.19 . (C) 2001 Elsevier Science B.V. All rights reserved.
\end{abstract}

Keywords: Nickel phthalocyanine; Nitric oxide sensor; Response current; Sensitivity

\section{Introduction}

Metal phthalocyanine thin films have been proposed for use as printing inks, colorants, photoconductors, solar cells, electrochromics, and gas sensors. As the for the sensor applications, the principle is based on the change of conductivity upon adsorption of gas species at the surface [1,2]. Most of the metal phthalocyanines (MPcs) [3-17] are p-type semiconductors with good thermal and chemical stabilities, whereas copper tetra-4-(2,4-di-tert-amylphenoxy) phthalocyanine (tap $\mathrm{CuPc})$ is a n-type semiconductor [18]. For p-type MPcs, their conductivity increases following adsorption of oxdizing molecules, because of the generation of hole carriers induced by the formation of charge transfer complexes at the surface of the phthalocyanines. It is well known that various gases in ambient environment can affect the semiconductivity of a number of metal phthalocyanines. A partial list of the metal phthalocyanines for gas-sensing is given in Table 1.

Even though the gas-sensing properties involving $\mathrm{NO}_{2}$ and MPcs, as shown in Table 1, are well studied, few studies have been carried out on exploring the gas-sensing properties of NO using metal phthalocyanines. The aim of this

\footnotetext{
* Corresponding author. Fax: +886-2-2362-3040.

E-mail address: kcho@ms.cc.ntu.edu.tw (K.-C. Ho).
}

research is to investigate the gas-sensing property of vacuum-deposited NiPc films for NO detection. Liu et al. [19] derived an unsteady-state current increment-time ( $\Delta I-$ $t)$ relation which takes into account the adsorption-desorption at the gas/thin film interface. Our experimental data for the current responses are consistent with this model. Various parameters, as defined in the model, have been extracted from the experimental results. The results showed that the lower the NO concentration, the larger the sensitivity. Moreover, the theoretical relationship between the film thickness and the response current, as predicted by the model, is verified experimentally. The effect on gas response characteristics will also be discussed.

\section{Experimental}

\subsection{Preparation}

Nickel phthalocyanine (NiPc) (Strem Chem. 94\%) was purified twice by sublimation in a vacuum glass tube at $5.0 \times 10^{-4}$ Torr and $500^{\circ} \mathrm{C}$. Purified powders were vaporized and condensed onto $\mathrm{Al}_{2} \mathrm{O}_{3}$ substrates in a difussionpumped vacuum system operating at a base pressure of $1.8 \times 10^{-5}$ Torr. $\mathrm{Al}_{2} \mathrm{O}_{3}$ substrates were screen-printed with gold interdigitated electrodes with $200 \mu \mathrm{m}$ electrode 
Table 1

A partial list of metal phthalocyanines for gas-sensing

\begin{tabular}{llll}
\hline MPcs & Types & Applicable gases & References \\
\hline $\mathrm{CuPc}$ & p-type & $\mathrm{NO}_{2}, \mathrm{NH}_{3}$ & {$[3]$} \\
$\mathrm{NiPc}$ & p-type & $\mathrm{NO}_{2}$ & {$[4]$} \\
$\mathrm{PbPc}$ & p-type & $\mathrm{NO}_{2}$ & {$[5-9]$} \\
& & $\mathrm{Cl}_{2}$ & {$[10]$} \\
& & $\mathrm{H}_{2}$ & {$[11]$} \\
$(\mathrm{AlPcF})_{n}$ & p-type & $\mathrm{NO}_{2}, \mathrm{O}_{2}$ & {$[12-14]$} \\
$\mathrm{Lu}(\mathrm{Pc})_{2}$ & p-type & $\mathrm{NO}_{2}, \mathrm{HCl}, \mathrm{H}_{2} \mathrm{~S}, \mathrm{SO}_{2}$ & {$[15]$} \\
$\mathrm{TiOPc}$ & p-type & $\mathrm{NO}_{2}$ & {$[16]$} \\
$\mathrm{FePc}$ & p-type & $\mathrm{NO}_{2}$ & {$[17]$} \\
$\operatorname{tap~CuPc}$ & n-type & $\mathrm{NH}_{3}$ & {$[18]$} \\
\hline
\end{tabular}

spacing. The evaporated NiPc films were deposited under vacuum as thin layers by controlling the evaporation rate and thickness. The deposition rates were kept between 0.1 and $5 \mathrm{~nm} / \mathrm{s}$, the substrate temperature was kept at $25^{\circ} \mathrm{C}$. Typical film thickness for gas-sensing experiments was maintained at $100 \mathrm{~nm}$ with an oscillating quartz-crystal thin film monitor. NO gas diluted with ultra-high purity $\mathrm{N}_{2}(99.9995 \%)$ was passed through the test chamber at flow rates of 100 $500 \mathrm{ml} / \mathrm{min}$, controlled by a mass flow controller (Sierra, Model 840). The dc conductivity of the NiPc sensing unit was measured using a power supply (Keithley, Model 236) with a source voltage of $10 \mathrm{~V}$. X-ray diffraction experiments were performed on a Rigaku diffractometer (Model RTP300RC) using monochromatized $\mathrm{Cu} \mathrm{K}_{\alpha}$ incident radiation.

\subsection{Sensing chamber}

The sensor was an alumina substrate $(12 \mathrm{~mm}$ square, $1 \mathrm{~mm}$ thick) with an interdigitated electrode pattern over which a thin NiPc film was vacuum-deposited. The sensor was mounted on a base located at the bottom of the sensing glass chamber, as shown in Fig. 1.

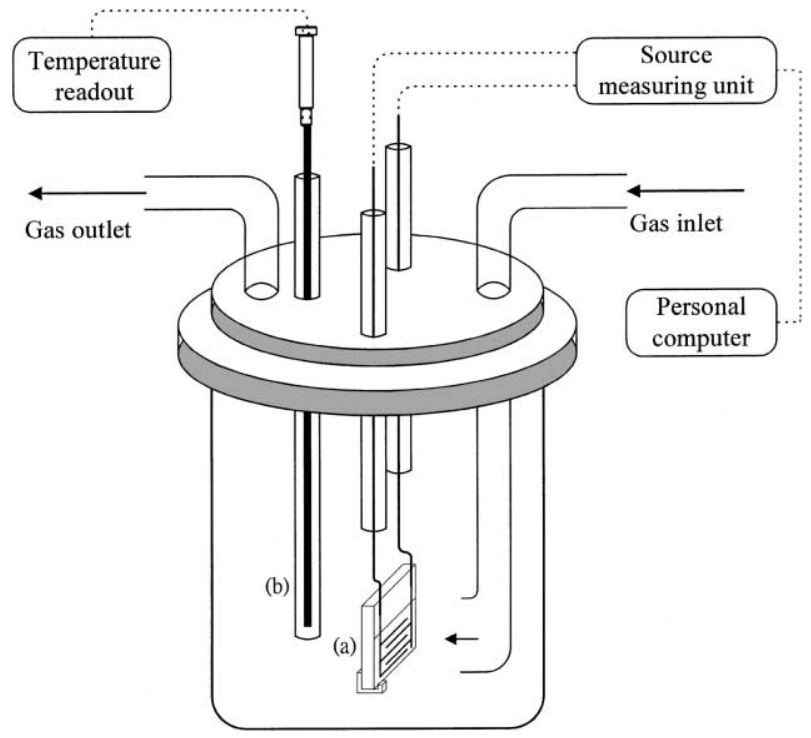

Fig. 1. Chamber design in a sensing unit: (a) NiPC-coated Auinterdigitated sensing electrode; (b) thermal couple.

\section{Elovich kinetics and equilibrium kinetics}

Passard et al. [14] observed two different kinetics for the interaction of the oxidizing gases $\mathrm{O}_{2}$ and $\mathrm{NO}_{2}$ with $(\mathrm{AlPcF})_{n}$ thin film. They proposed a doping mechanism to separate the physical process from the chemical process. For a constant heat of adsorption, independent of the surface coverage, the chemisorption kinetics [1] follow the Elovich equation:

$\frac{\mathrm{d} \theta}{\mathrm{d} t}=a \exp (-b \theta)$

It can be seen from Eq. (1) that the fractional surface coverage $(\theta)$, and hence the conductivity or the net sensing current, varies linearly with $\log ($ time $)$ rather than with linear time. Archer et al. [8] used the Elovich equation to explain the kinetic data for the adsorbed $\mathrm{NO}_{2}$ on PbPc. With adequate time allowed for the attainment of surface coverage equlibrium, Liu et al. [19] recently used a simple adsorption-desorption equilibrium model to interpret the response characteristics of $\mathrm{NO}_{2}-\mathrm{PbPc}$ interaction. As our typical current response data for the NO-NiPc interaction does not indicate two dramatically different kinetic processes and that the Elovich kinetics is suitable only for a qualitative explanation, we will adopt the following adsorption-desorption equilibrium model and assume that the pseudo-equilibrium state can be achieved within the time interval of interest:

$\mathrm{NO}(\mathrm{g})+\mathrm{NiPc}($ surface $) \rightleftharpoons \mathrm{NONiPc}$

Let us assume that $k_{\mathrm{a}}$ and $k_{\mathrm{d}}$ represent the rate constants for adsorption and desorption, respectively. A total site balance gives

$\frac{\mathrm{d} N_{\mathrm{s}}(t)}{\mathrm{d} t}=k_{\mathrm{a}} C_{0}\left[N_{0}-N_{\mathrm{s}}(t)\right]-k_{\mathrm{d}} N_{\mathrm{s}}(t)$

where $C_{0}$ is the bulk concentration of $\mathrm{NO}, N_{\mathrm{s}}$ the surface concentration of the adsorbed NO, $N_{0}$ the total sites concentration available on the surface, and $\left[N_{0}-N_{\mathrm{s}}(t)\right]$ represents the surface concentration of the unoccupied sites. The surface coverage, $\theta$, is defined as the ratio of the adsorbed sites concentration to that of the total sites concentration, i.e.

$\theta=\frac{N_{\mathrm{s}}}{N_{0}}$

Eq. (3) becomes

$\frac{\mathrm{d} \theta}{\mathrm{d} t}=k_{\mathrm{a}} C_{0}[1-\theta]-k_{\mathrm{d}} \theta$

The equation can be solved with the initial condition of $\theta(0)=0$. The surface coverage, $\theta$, as a function of time, is written as

$\theta=\frac{K C_{0}}{1+K C_{0}}\left[1-\exp \left(-\left(k_{\mathrm{a}} C_{0}+k_{\mathrm{d}}\right) t\right)\right]$ 
where $K=k_{\mathrm{a}} / k_{\mathrm{d}}$ is the equilibrium constant. For simplicity, we assumed that the net sensing current $(\Delta I)$ resulting from the adsorption-desorption process is proportional to the adsorbed gas concentration, $N_{\mathrm{s}}$, or the surface coverage, $\theta$, i.e.

$\Delta I=k \theta(t)$

where $k$ is the proportionality constant. The net sensing current can be put into the following form:

$\Delta I=\Delta I_{\mathrm{ss}}\left[1-\exp \left(-\left(k_{\mathrm{a}} C_{0}+k_{\mathrm{d}}\right) t\right)\right]$

where $\Delta I_{\mathrm{ss}}$ is the steady-state current, and is defined as

$\Delta I_{\mathrm{ss}}=\frac{k K C_{0}}{1+K C_{0}}=k \theta(\infty)$

In gas sensor application, a power law of the form $\Delta I \propto C_{0}^{S}$ is observed [20]. The power $S$ can be determined from the slope of the all-logarithm plot of $\Delta I$ versus $C_{0}$, i.e.

$S=\frac{\mathrm{d} \ln (\Delta I)}{\mathrm{d} \ln C_{0}}=\frac{\mathrm{d} \log (\Delta I)}{\mathrm{d} \log C_{0}}$

The value of $S$ stands for the relative sensitivity of the thin film.

\section{Results and discussion}

Previous workers have studied the effect of the $\mathrm{NO}_{2}$ concentration on the current response of NiPc films, but the NO concentration effect on the sensing properties of $\mathrm{NiPc}$ films has not been discussed before. The present data, together with other related published results, now permit a fuller discussion of the sensing characteristics for the interaction between NO gas and NiPc thin films.

\subsection{Morphology}

It is well known that the morphology of the vacuumdeposited metal phthalocyanines thin film depends on its growth conditions. For NiPC films deposited on $\mathrm{Al}_{2} \mathrm{O}_{3}$ substrates at rates between 0.1 and $5 \mathrm{~nm} / \mathrm{s}$ and substrate temperature of $25^{\circ} \mathrm{C}$, XRD data in Fig. 2 show the same peak positions for all of the samples. There is only one small peak which is not due to the underlying $\mathrm{Al}_{2} \mathrm{O}_{3}$ substrate, but the characteristic peak at $2 \theta=6.3^{\circ}$ for the $\alpha$-phase NiPc.

\subsection{Response characteristics}

Upon exposure to $\mathrm{NO}$ gas, the electrical conductivity of the NiPc film increases. Fig. 3 shows the response characteristics of $\mathrm{NiPc}$ films when exposed to $250 \mathrm{ppm} \mathrm{NO}$ in $\mathrm{N}_{2}$ at $160^{\circ} \mathrm{C}$. The inset in Fig. 3 is a replot of current versus $\log$ (time) with data taken from Fig. 3. A straight line can be obtained with no sign of reaching equlibrium within $60 \mathrm{~min}$. Note that the response of the NiPc film is rather slow; generally it takes more than $500 \mathrm{~min}$ to reach the

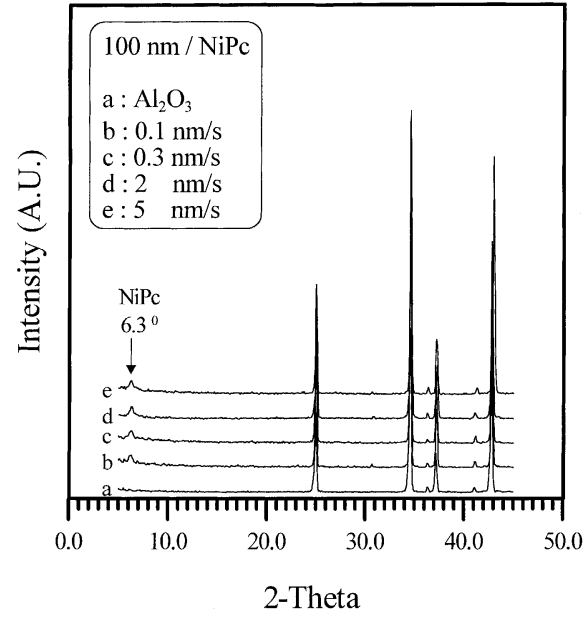

Fig. 2. XRD diagrams of NiPc film prepared under various evporation rates set at $0.1,0.3,2.0$, and $5.0 \mathrm{~nm} / \mathrm{s}$. Film thickness: $100 \mathrm{~nm}$, substrate temperature: $25^{\circ} \mathrm{C}$, substrate material: $\mathrm{Al}_{2} \mathrm{O}_{3}$.

pseudo-steady-state. It can be found from Fig. 4 that, for $\mathrm{NiPc}$ films made with the same thickness, i.e. $100 \mathrm{~nm}$, the faster the deposition rate, the sooner it will take to reach the pseudo-steady-state, and the smaller the response current.

\subsection{Concentration effect}

The response currents of a typical NiPc film exposed to different NO concentrations, following an increasing concentration order of $5,10,20,40,50,100,300$, and $500 \mathrm{ppm}$, were recorded. Fig. 5 shows the consecutive current responses when NO concentrations were increased sequentially from 5 to $500 \mathrm{ppm}$. Both adsorption and desorption times were set at $20 \mathrm{~min}$. At the end of each desorption, the surface still contained traces of NO adsorbed at some

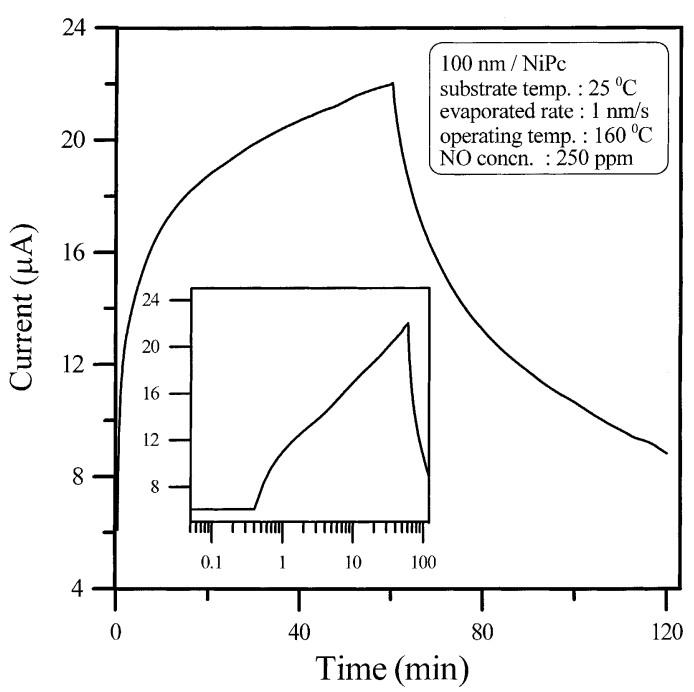

Fig. 3. Response current of NiPc film exposed to $250 \mathrm{ppm} \mathrm{NO}$ in $\mathrm{N}_{2}$ at $160^{\circ} \mathrm{C}$ with film thickness: $100 \mathrm{~nm}$, substrate temperature: $25^{\circ} \mathrm{C}$, evaporation rate: $1 \mathrm{~nm} / \mathrm{s}$, mass flow rate $200 \mathrm{ml} / \mathrm{min}$. The inset is a replot of current vs. $\log ($ time$)$, showing the slow Elovich kinetics. 


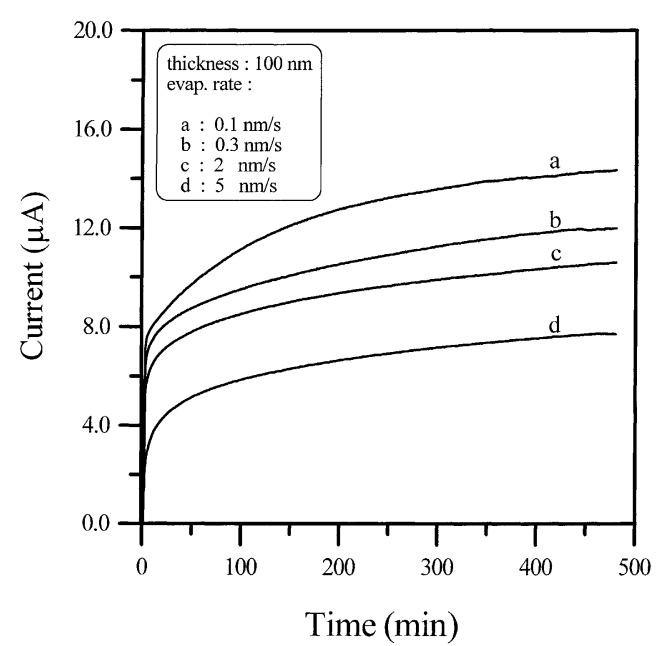

Fig. 4. Response currents of NiPc films deposited at various evaporation rates. The films were continuously exposed to $250 \mathrm{ppm} \mathrm{NO}$ in $\mathrm{N}_{2}$ at $160^{\circ} \mathrm{C}$ for $8 \mathrm{~h}$ with film thickness: $100 \mathrm{~nm}$, substrate temperature: $25^{\circ} \mathrm{C}$, mass flow rate $200 \mathrm{ml} / \mathrm{min}$.

adsorption sites, unless the desorption process was allowed to continue for a very long time. This is consistent with a kinetic model [8], proposed for $\mathrm{NO}_{2}$ sensor using $\mathrm{PbPc}$ thin films, in which adsorption involves the displacement of surface adsorbed oxygen from a range of heterogeneous sites. Although ultra-high purity $\mathrm{N}_{2}$ was used in this study, the purity level still allows 5 ppm of oxygen. Fig. 6 is a plot for the current increase versus NO concentration. The circles in Fig. 6 were obtained from the experimental data, while the curve is a model fit based on the adsorption-desorption kinetics with $k=10.10 \mu \mathrm{A}$ and $K=0.042 \mathrm{ppm}^{-1}$. The sensitivity plot in Fig. 7 gives the sensitivity $(S)$ values of 0.413 and 0.174 for $\mathrm{NO}$ concentrations in the ranges 5-50 ppm and 50-500 ppm, respectively. It is worthwhile to

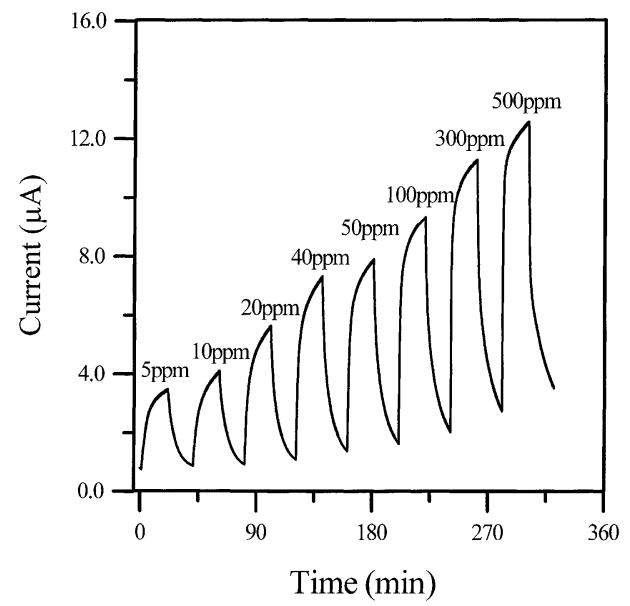

Fig. 5. Response current of NiPc film sequentially exposed to 5, 10, 20, $40,50,100,300$, and $500 \mathrm{ppm} \mathrm{NO}$ in $\mathrm{N}_{2}$ at $160^{\circ} \mathrm{C}$. Film thickness: $100 \mathrm{~nm}$, substrate temperature: $25^{\circ} \mathrm{C}$, evaporation rate: $0.1 \mathrm{~nm} / \mathrm{s}$, mass flow rate $200 \mathrm{ml} / \mathrm{min}$, adsorption time: $20 \mathrm{~min}$, desorption time: $20 \mathrm{~min}$ without aerating $\mathrm{N}_{2}$.

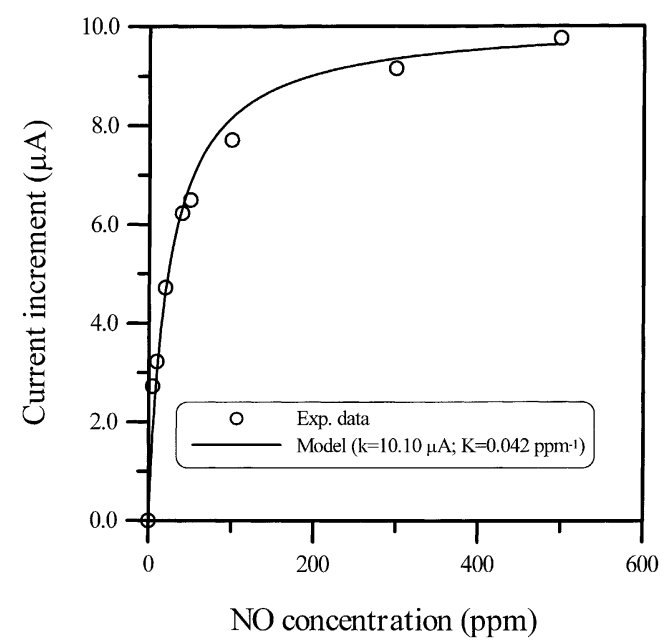

Fig. 6. Current increase of NiPc film sequentially exposed to 5, 10, 20, 40, $50,100,300$, and $500 \mathrm{ppm} \mathrm{NO}$ in $\mathrm{N}_{2}$ at $160^{\circ} \mathrm{C}$. Operating conditions are the same as those in Fig. 5. The circles are obtained from the experimental data, while the curve is a model fit based on the adsorption-desorption kinetics.

mention that the reported $S$ values are the pseudo-sensitivity data, as the circles in Fig. 6 represent the pseudo-equilibrium data.

In order to test the reversibility of the NO-NiPc interaction, the same NiPc film exposed to different NO concentrations, following the reverse concentration order in Fig. 5, were also recorded. Figs. 8-10 are the corresponding results for the concentration variation following the decreasing concentration order. In this sensing experiment, adsorption time was set at $20 \mathrm{~min}$ while complete desorption was ensured by allowing the current to return to the background value, as shown in Fig. 8. The fact that these desorption times become shorter as the NO concentration decreases is strong evidence that adsorption involves displacement of

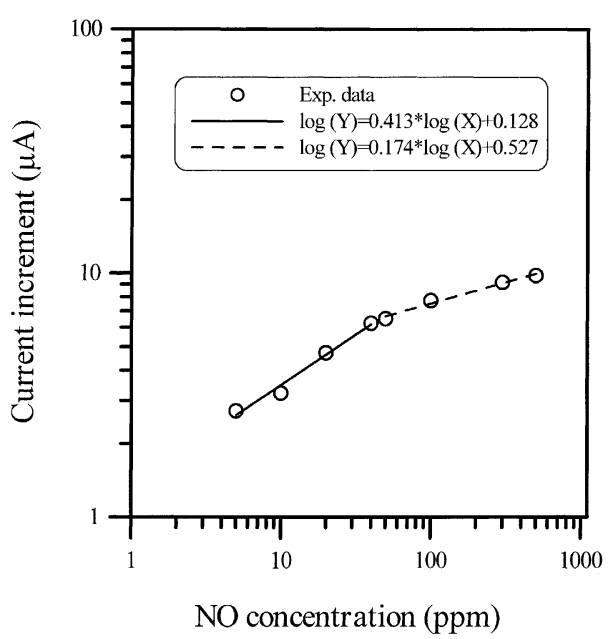

Fig. 7. All-logarithm plot of current increasement vs. NO concentration, showing the sensitivity of NiPc film on NO sensing. Operating conditions are the same as those in Fig. 5. The circles were obtained from the experimental data, while the straight lines are the best model fits. 


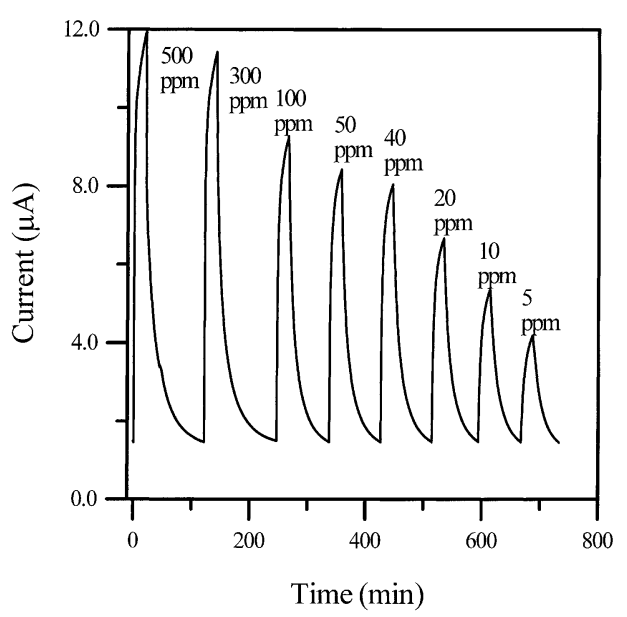

Fig. 8. Response current of NiPc film sequentially exposed to 500, 300, $100,50,40,20,10$, and $5 \mathrm{ppm} \mathrm{NO}$ in $\mathrm{N}_{2}$ at $160^{\circ} \mathrm{C}$. Film thickness: $100 \mathrm{~nm}$, substrate temperature: $25^{\circ} \mathrm{C}$, evaporation rate: $0.1 \mathrm{~nm} / \mathrm{s}$, mass flow rate $200 \mathrm{ml} / \mathrm{min}$, adsorption time: $20 \mathrm{~min}$, desorption time: desorpted completely without any gas.

surface adsorbed $\mathrm{O}_{2}$ from a range of heterogeneous sites, as proposed by Archer et al. [8] and Wilson et al. [9]. Hence the sensing mechanism for $\mathrm{NiPc}$ involving $\mathrm{NO}$ and $\mathrm{O}_{2}$ can be described as follows: exposure to low NO concentrations only involve the population of weak adsorption sites, from which $\mathrm{O}_{2}$ is readily displaced, hence, the reversal is rapid; exposure to higher NO concentrations involves the population of stronger adsorption sites, which are depopulated more slowly on reversal. Fig. 9 is a plot of the current increase versus NO concentration. The circles in Fig. 9 were obtained from the experimental data, while the curve is a model fit based on the adsorption-desorption kinetics with $k=10.87 \mu \mathrm{A}$ and $K=0.041 \mathrm{ppm}^{-1}$. The sensitivity plot in Fig. 10 gives the sensitivity $(S)$ values of 0.186 and 0.423 for NO concentrations in the ranges $500-50 \mathrm{ppm}$ and

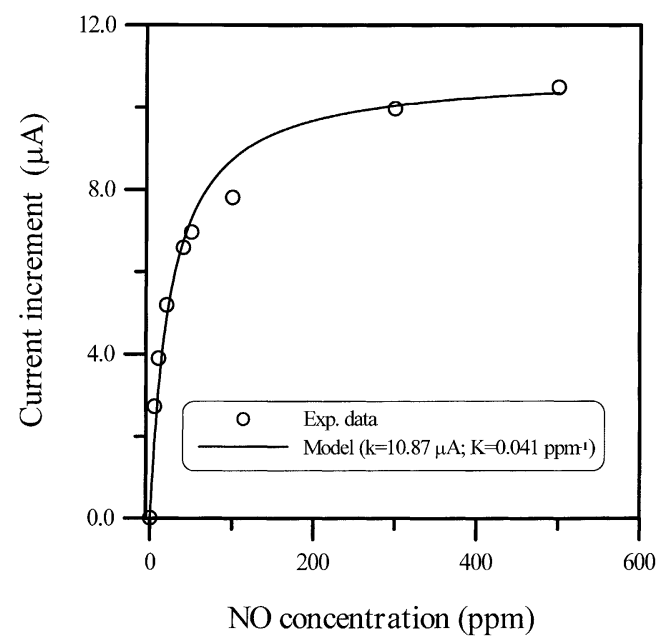

Fig. 9. Current increase of NiPc film sequentially exposed to 500, 300, $100,50,40,20,10$, and $5 \mathrm{ppm} \mathrm{NO}$ in $\mathrm{N}_{2}$ at $160^{\circ} \mathrm{C}$. Operating conditions are the same as those in Fig. 8. The circles are obtained from the experimental data, while the curve is a model fit based on the adsorptiondesorption kinetics.

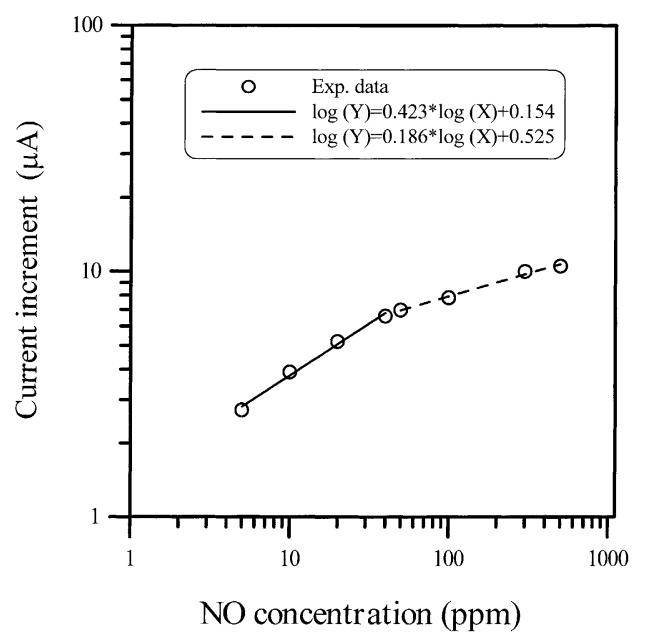

Fig. 10. All-logarithm plot of current increasement vs. NO concentration, showing the sensitivity of NiPc film on NO sensing. Operating conditions are the same as those in Fig. 8. The circles were obtained from the experimental data, while the straight lines are the best model fits.

50-5 ppm, respectively. In fact, the sensitivity of the NO$\mathrm{NiPc}$ interaction decreases when the NO concentration is increased from low to high with a transition occurring at about 50 ppm, as shown both in Figs. 7 and 10. Therefore, it is concluded that exposure to NO concentrations lower than $50 \mathrm{ppm}$ only involves the population of weak adsorption sites, while exposure to NO concentrations higher than $50 \mathrm{ppm}$ involves the population of stronger adsorption sites. Table 2 summarizes the values of the best fitted parameters, $k$ and $K$, and the sensitivity $S$. The sensitivity depends on the concentration range of NO. For a higher concentration range, between 50 and $500 \mathrm{ppm} \mathrm{NO}$, the sensitivity lies between 0.174 and 0.186 , while for a lower concentration range, between 5 and $50 \mathrm{ppm}$, the sensitivity increases to about $0.413-0.423$. Therefore, it is expected that the sensitivity would be improved when NiPc films were used for sensing low concentration NO.

\subsection{Mass flow rate/cooling effect}

The effect of the mass flow rate or the cooling effect on the current responses of NiPc film exposed to $5 \mathrm{ppm} \mathrm{NO}$ in $\mathrm{N}_{2}$ is shown in Fig. 11. The preparation and operating parameters are: film thickness: $100 \mathrm{~nm}$, substrate temperature: $25^{\circ} \mathrm{C}$, operating temperature: $160^{\circ} \mathrm{C}$, evaporation rate: $0.1 \mathrm{~nm} / \mathrm{s}$, adsorption time: $20 \mathrm{~min}$, desorption time: complete desorption without any gas. No attempt was made to pre-heat the

Table 2

Effect of concentration range on the sensitivity

\begin{tabular}{clll}
\hline$C_{0}(\mathrm{ppm})$ & $k(\mu \mathrm{A})$ & $K\left(\mathrm{ppm}^{-1}\right)$ & $S$ \\
\hline $5-50$ & 10.10 & 0.042 & 0.413 \\
$50-500$ & 10.10 & 0.042 & 0.174 \\
$500-50$ & 10.87 & 0.041 & 0.186 \\
$50-5$ & 10.87 & 0.041 & 0.423 \\
\hline
\end{tabular}




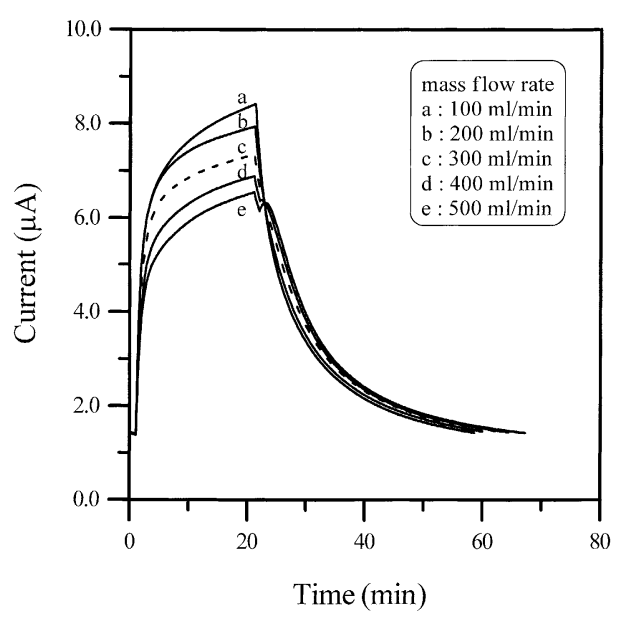

Fig. 11. The effect of mass flow rate on the current response of NiPc film exposed to $5 \mathrm{ppm} \mathrm{NO}$ in $\mathrm{N}_{2}$. Film thickness: $100 \mathrm{~nm}$, substrate temperature: $25^{\circ} \mathrm{C}$, operating temperature: $160^{\circ} \mathrm{C}$, evaporation rate: $0.1 \mathrm{~nm} / \mathrm{s}$, adsorption time: $20 \mathrm{~min}$, desorption time: complete desorption without any gas.

gas to the same temperature as the sensing chamber before admitting the gas to the chamber. The temperature in the chamber reached a steady-state value $20 \mathrm{~min}$ after the gas was allowed into the chamber. The steady-state temperatures recorded were $160,159.5,159,158$, and $157^{\circ} \mathrm{C}$ for curves (a)-(e), respectively. The results indicate that, under the same NO cencentration, the larger the mass flow rate, the larger the cooling effect, and thus the smaller the response current. The cooling effect may be neglected in a realistic sensing as usually the mass flow rate is rather low.

\subsection{Repeated sensing}

Repeated sensing was carried in a $50 \mathrm{ppm} \mathrm{NO}$ with $\mathrm{N}_{2}$. Fig. 12 shows the result from the repeated sensing current. During sensing, adsorption time was set at $20 \mathrm{~min}$ while

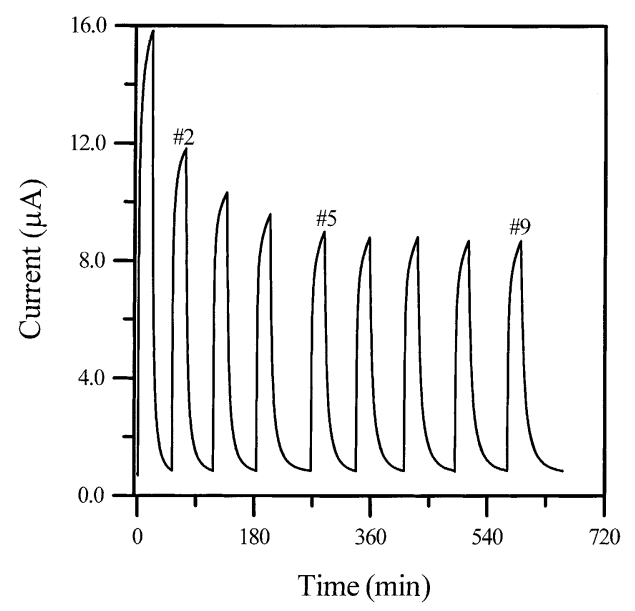

Fig. 12. Repeated response current of NiPc film exposed to $50 \mathrm{ppm}$ NO in $\mathrm{N}_{2}$ at $160^{\circ} \mathrm{C}$ for the first nine cycles. Film thickness: $100 \mathrm{~nm}$, substrate temperature: $25^{\circ} \mathrm{C}$, evaporation rate: $0.1 \mathrm{~nm} / \mathrm{s}$, mass flow rate $200 \mathrm{ml} / \mathrm{min}$, adsorption time: $20 \mathrm{~min}$, desorption time: desorpted completely without any gas. complete desorption was ensured by allowing the current to return to the background value. It can be seen from Fig. 12 that the sensing becomes reasonably stable afer five sensing cycles, which is acceptable in a realistic sensing environments.

\section{Conclusions}

This work reported on the sensing characteristics of nickel phthalocyanine ( $\mathrm{NiPc}$ ) thin films for use in a chemiresistortype nitric oxide gas sensor. The main conclusions from this study are as follows.

1. A kinetic model proposed in the literature for the $\mathrm{NO}_{2}-$ $\mathrm{PbPc}$ interaction, in which adsorption involves displacement of surface adsorbed $\mathrm{O}_{2}$ from a range of heterogeneous sites, can be used to explain our experimental results for the NO-NiPc interaction. We concluded that exposure to $\mathrm{NO}$ concentrations lower than $50 \mathrm{ppm}$ only involves the population of weak adsorption sites, while exposure to NO concentrations higher than $50 \mathrm{ppm}$ may involve the population of stronger adsorption sites. Our experimental data for the current response were qualitatively consistent with the model.

2. Quantitatively, we adopted the pseudo-steady-state current increment versus time ( $\Delta I$ versus $t$ ) relationship based on the adsorption-desorption process at the gas/thin film interface to quantify the sensitivity and model parameters. The sensing results of NO with NiPcs showed that the lower the NO concentration, the larger the sensitivity. For a lower concentration range, between 5 and $50 \mathrm{ppm} \mathrm{NO}$, the sensitivity lies between 0.41 and 0.42 , while for a higher concentration range, between 50 and $500 \mathrm{ppm}$, the sensitivity decreases to about 0.17 to 0.19 .

3. The experimental data revealed that repeated step changes in a NO concentration of $50 \mathrm{ppm}$ could result in a significant change in response currents for the first five sensing cycles, presumably due to the presence of an irreversible adsorption. The sensing becomes relatively stable after five sensing cycles.

4. It is possible to fabricate chemiresistor-type sensors using MPc thin films with $\mathrm{M}$ being nickel for sensing $\mathrm{NO}$ gas in the concentration range below $50 \mathrm{ppm}$.

\section{Acknowledgements}

This work was sponsored by the National Research Council of the Republic of China under Grant No. NSC 88-2214-E002-022.

\section{References}

[1] J.R. Bates, M. Campbell, Gas sensors and analysers, in: M. Campbell (Ed.), Sensor Systems for Environmental Monitoring, Vol. 1, Sensor Technologies, Blackie, London, 1997, pp. 152-156. 
[2] H. Laurs, G. Heiland, Electrical and optical properties of phthalocyanine films, Thin Solid Films, 149 (1987) 129-142.

[3] C. Park, D.H. Yun, S.-T. Kim, Y.W. Park, Enhancement of the $\mathrm{NO}_{2}$ sensing capability of copper phthalocyanine by measuring the relative resistance change, Sens. Actuators B 30 (1996) 23-27.

[4] A. Belghachi, R.A. Collins, The effects of humidity on phthalocyanine $\mathrm{NO}_{2}$ and $\mathrm{NH}_{3}$ sensors, J. Phys. D: Appl. Phys. 23 (1990) 223-227.

[5] J.W. Gardner, M.Z. Iskandarani, B. Bott, Effect of electrode geometry on gas sensitivity of lead phthalocyanine thin films, Sens. Actuators B 9 (1992) 133-142.

[6] G.P. Rigby, A. Wilson, J.D. Wright, S.C. Thorpe, Fast-response heat treated lead phthalocyanine $\mathrm{NO}_{2}$ sensors, in: Sensors Technology, Systems and Applications, IOP Publishing Ltd., Philadelphia, 1991, pp. 121-126.

[7] B. Bott, T.A. Jones, A highly sensitive $\mathrm{NO}_{2}$ sensor based on electrical conductivity changes in phthalocyanine films, Sens. Actuators 5 (1984) 43-53.

[8] P.B.M. Archer, A.V. Chadwick, J.J. Miasik, M. Tamizi, J.D. Wright, Kinetics factors in the response of organometallic semiconductor gas sensors, Sens. Actuators 16 (1989) 379-392.

[9] A. Wilson, J.D. Wright, A.V. Chadwick, A microprocessor-controlled nitrogen dioxide sensing system, Sens. Actuators B 4 (1991) 499-504.

[10] A.T.J. Perr, A. Krier, R.A. Collins, Adsorption and bulk diffusion of chlorine in monoclinic lead phthalocyanine thin film gas sensors, Thin Solid Films 230 (1993) 225-228.

[11] S. Kanefusa, M. Nitta, The detection of $\mathrm{H}_{2}$ gas by metal phthalocyanine-based gas sensors, Sens. Actuators B 9 (1992) 85-90.

[12] M. Dugay, C. Maleysson, Thin layer of poly(fluoroaluminumphthalocyanine), Synth. Met. 21 (1987) 255-260.

[13] C. Maleysson, D. Bouche-Pillon, O. Tomas, J.-P. Blanc, S. Dogo, J.P. Germain, M. Passard, A. Pauly, Conductivity and gas species content of $(\mathrm{AlPcF})_{n}$ thin films exposed to $\mathrm{O}_{2}$ or $\mathrm{NO}_{2}$, Thin Solid Films 239 (1994) 161-165.

[14] M. Passard, A. Pauly, J.-P. Blanc, S. Dogo, J.-P. Germain, C. Maleysson, Doping mechanisms of phthalocyanines by oxidizing gases: application to gas sensors, Thin Solid Films 237 (1994) 272-276.

[15] M. Trometer, R. Evan, J. Simon, A. Dubon, J. Laval, J.P. Germain, C. Maleysson, A. Pauly, H. Robert, Lutetium bisphthalocyanine thin films for gas detection, Sens. Actuators B 8 (1992) 129-135.
[16] C.J. Liu, C.H. Peng, Y.H. Ju, J.C. Hsieh, Titanyl phthalocyanine gas sensor for $\mathrm{NO}_{2}$ detection, Sens. Actuators B 52 (1998) 264-269.

[17] J.K. O'Rourke, J.S. Brooks, N.A. Bell, J. Cawley, Mossbauer and microstructural studies of iron phthalocyanine as a potential gas sensor, Sens. Actuators B 15/16 (1993) 90-97.

[18] D.P. Jiang, A.D. Lu, Y.J. Li, X.M. Pang, Y.L. Hua, Interaction between copper tetra-4-(2,4-di-tert-amylphenoxy) phthalocyanine Langmuir-Blodgett films as a gas-sensitive sensor and $\mathrm{NH}_{3}$, Thin Solid Films 199 (1987) 173-179.

[19] C.J. Liu, J.C. Hsieh, Y.H. Ju, Response characteristics of lead phthalocyanine gas sensor: effect of operating temperature and postdeposition annealing for $\mathrm{NO}_{2}$ detection, J. Vac. Sci. Technol. A 14 (1996) 753-756.

[20] H.-Y. Wang, J.B. Lando, Gas-sensing mechanism of phthalocyanine Langmuir-Blodgett films, Langmuir, 10 (1994) 790-796.

\section{Biographies}

Kuo-Chuan Ho received his BS and MS degrees in Chemical Engineering from National Cheng Kung University, Tainan, Taiwan, in 1978 and 1980, respectively. In 1986, he received the $\mathrm{PhD}$ degree in Chemical Engineering at the University of Rochester. The same year he joined PPG Industries, Inc., first as a Senior Research Engineer and then, from 1990 until 1993, as a Research Project Engineer. He has worked on the electrochemical properties of various electrode materials. He has applied surface science/ interfacial engineering and electrochemistry/electrochemical engineering principles for improving the performances of sensor devices, with emphasis on electrochemical, at rest, and thermal stabilities. Following a 6-year industrial career at PPG Industries, Inc., he joined his alma mater, National Cheng Kung University, in 1993 as an Associate Professor in the Chemical Engineering Department. In 1994, he moved to the Department of Chemical Engineering at National Taiwan University. Currently, he is a Professor there.

Yi-Ham Tsou received his MS degree in Chemical Engineering from National Taiwan University, Taipei, Taiwan, in 1997. After 2 years compulsory military service, he is now a process engineer at United Microelectronics Corporation based in Hsin-Chu, Taiwan. His research interests include gas sensors and semiconductor processing and fabrication. 